\title{
AÇÃO CIVIL PÚBLICA EM MATÉRIA AMBIENTAL E DENUNCIAÇÃO DA LIDE
}

\author{
Ada Pellegrini Grinover \\ Professora Titular do Departamento de Direito Processual \\ da Faculdade de Direito da Universidade de São Paulo
}

Resumo:

O estudo analisa a responsabilidade objetiva por dano ambiental, cujo reconhecimento depende da comprovação do dano e do nexo causal. A seguir, detém-se sobre a denunciação da lide, espécie de intervenção de terceiros concebida como instituto apto a chamar em juizo um terceiro, com o qual a parte tenha uma relação de regresso na eventualidade de perder a demanda. E, finalmente, sustenta o cabimento da denunciação da lide na Ação Civil Pública por dano ambiental.

Abstract:

This article studies the objective liability due to ambiental damages, that depends on the evidence of the damage and the causal relationship. After that, it observes the procedural institute of the third intervention conceived in order to call to the action a third whom the parties may have with a right of regression if they would lost the judgement. And, finally, it defends the possibility of this kind of intervention in Brazilian class actions for ambiental damage.

Unitermos: ação civil pública; dano ambiental; dano e nexo causal; denunciação da lide; cabimento.

O presente estudo objetiva examinar a possibilidade de denunciação da lide no âmbito da ação civil pública em matéria ambiental, sem embargo da responsabilidade objetiva que vigora nessa matéria.

1. Responsabilidade objetiva: existência do dano e nexo causal.

Como sabido, a Lei n. 6.938/81, que instituiu a Política Nacional do Meio Ambiente, deu tratamento à matéria de responsabilidade ambiental e, em seu art. 14 , parágrafo $1^{\circ}$. consagrou o regime da responsabilidade objetiva, obrigando todo e qualquer poluidor, agente causador da degradação ambiental, independentemente da 
existência de culpa, a indenizar ou reparar os danos causados ao meio ambiente e a terceiros, aletados por sua atividade'

Portanto, a configuração dessa forma de responsabilidade civil depende, no Direito Positivo brasileiro, da existência de um dano ao meio ambiente e do nexo causal com a atividade do agente ${ }^{2}$ Nesse sentido, José Afonso da Silva observou que o "direito brasileiro assume o princípio da responsabilidade objetiva pelo dano ecológico, o que é una tendência do direito estrangeiro como mostra Paulo Affonso Leme Machado. Segundo Despax é muito nítida no direito francês a evolução para uma responsabilidade objetiva, acompanhada de uma diminuição do ônus da prova da exigência do nexo de causalidade entre o prejuizo sofrido e a atividade danosa ao meio ambiente. (...). Na responsabilidade objetiva por dano ambiental, basta a existência do dano e nexo com a fonte poluidora ou degradadora"3 (grifei).

Também a propósito do tema, Nelson Nery Júnior e Rosa Maria de Andrade Nery lembram que a lei brasileira adotou " $a$ teoria do risco da atividade para estipular a responsabilidade objetiva para a reparação do dano causado ao meio ambiente ( $L 6.938 / 91 / 4 \$ I^{\circ}$ ), de sorte que basta a existência do dano e do nexo causal para que haja o dever de indenizar (...)"4 (grifei). E anotam:

"Dano Ambiental. Prova. O dever de indenizar o dano ambiental é
caracterizado pelo nexo causal estabelecido entre a autoria e a causa,
não abrangendo o liame entre a causa e o efeito danoso. O autor da ação
de indenização tem o ônus de provar que o poluidor praticou o ato do
qual se originou o evento danoso. O dano, na verdade, se presume, porque
virtual. Cabe ao réu elidir a presunção. Em sentido mais ou menos
conforme, CSMP-SP /8: 'Em matéria de dano ambiental, a Lei n. $6.938 /$

1. A responsabilização por danos ambientais foi postcriormente tratada também pclo art. 225, parágrafo 3", da Constituiçào Fedcral de 1988, ao detcrminar que "as condlutas e atividades consideradas lesivas ao meio ambiente sujeitarão os infiratores, pessoas fisicas ou juridlcas, a sançōes penais e administrativas, independentemente da obrigação de reparar os danos" A norma legal citada acima no texto, nào há dúvida, foi recepcionada pcla nova ordem constitucional c está cm plcno vigor (ct., nesse scntido, Cclso Antonio Pacheco Fiorillo c Marcclo Abelha Rodrigues, Manual de direito ambiental e legislação aplicável, São Paulo, 1999, Max Limonad, p. 125).

2. O dano ambiental ć do dano ao meio ambiente. Estc, nas palavras de Paulo de Bessa Antuncs, pode ser entendido como "um bem juridico autônomo e unitário, que não se confinde com os diversos bens juridicos que o integram. O bem juridico meio ambiente não é simples somatório de flora e fauna. de recursos hidricos e recursos minerais. $O$ bem juridico ambiente resulta da supressão de todos os componentes que, isoladamente, podem ser identificados, tais como florestas, animais, ar etc. Este conjunto de bens adquire uma particularidade juridica que é derivada da própria integraçào ecológica de seus elementos componentes" (cf. Direito ambiental, Rio de Janciro, Editora Lumen Juris, 5 ediçào, 200 I, p. 168).

3. Cf. Dircito ambiental constitucional, São Paulo, Malhciros Editores, 2' cdiçào, 2001, p. 215.

4. Cf. Código de processo civil comentado e legislação processual extravagante em vigor, Sào Paulo, Revista dos Tribunais, 5" cdiçào, 2001, p. 1.520. 
81 estabeleceu a responsabilidade objetiva, o que afasta a investigação e a discussão da culpa, mas não se prescinde de nexo causal entre o dano havido e a ação ou omissão de quem cause o dano. Se o nexo não é estabelecido, é caso de arquivamento do inquérito civil ou das peças de informação" "s. (grifei)

Ainda Nelson Nery Júnior, em outra obra, enfatizou que, nessa seara, para se caracterizar a responsabilidade objetiva é necessária a presença da conexão causal, ao asseverar que a "responsabilidade objetiva faz com que os pressupostos do dever de indenizar sejam apenas o evento danoso e o nexo de causalidade. A eventual aplicação de sanção administrativa prevista nos ns. II, III, IV do art. I4 da Lei 6.938/ 81 não elide o dever de indenizar o dano causado ao meio ambiente. A defesa do poluidor é limitada à negação da atividade e à inexistência do dano. (...) O nexo de causalidade é exigido como requisito para que se reconheça o dever de indenizar, quer se trate de responsabilidade objetiva, quer da subjetiva" E mais:

"O que é necessário, isto sim, é a presença da conexão causal, vale dizei, relação de causa e efeito entre a atividade do agente e o dano dela advindo." (grifei)

Assim também consignou Adalberto Pasqualotto, ao observar que "dois são os requisitos geralmente mencionados como suficientes à configuração da responsabilidade por prejuizos causados ao meio-ambiente: apenas o dano e o nexo de causalidade" Daí porque Hely Lopes Meirelles ensinou que a "responsabilidade do réu na ação civil pública é objetiva, pois independe de culpa no fato que a enseja (art. 14, $\$ 1^{\circ}$, da Lei 6.938/81), bastando que o autor demonstre o nexo causal entre a conduta do réu e a lesão ao meio ambiente a ser protegido $e$ indiqué o dispositivo legal infringido"" (grifei).

Nesse mesmo diapasão, Heraldo Garcia Vitta observou que "em face das regras do ordenamento, temos de admitir haver diferenças profundas entre a responsabilização por dano civil do direito privado e a responsabilização por dano ambiental. Nesta última, não há necessidade de o ato ser ilícito e não se perquire a culpa do autor do dano. Basta a demonstração do: a) causador da conduta ou atividade (ou da omissão); b) dano ambiental; c) nexo causal entre a ação ou omissão." E Rui

5. Cf. op. cit., p. 1523. A sigla usada na citação se referc a cnunciado ou súmula do Consclho Supcrior do Ministério Público de São Paulo.

6. "Responsabilidade civil, meio-ambiente c ação colctiva ambicntal", in Dano ambiental, prevenç̧io, reparação e repressão, Coordenador Antonio Herman V. Benjamin, São Paulo, Editora RT, 1993, pp. $280 / 281$,

7. "Responsabilidade civil por dano ambiental: considerações de ordem matcrial c processual", in Dano ambiental, prevenção, reparạ̧ão e repressão, Coordenador Antonio Herman V. Benjamin, São Paulo, Editora RT, 1993, p. 453.

8. "Protç̧ão ambiental c ação civil pública", RT 611/7, p. 11.

9. O meio ambiente e a ação popular, Sào Paulo, Editora Saraiva, 2000, pp. 25/26. 
Carvalho Piva completou, afirmando que "a justificativa teórica para a elaboração legislativa nos moldes acima mencionados é a teoria do risco integral, para a qual a responsabilidade advém de uma simples verificação de saber se deste evento emanou o dano"'". (grifei)

Calcada nessas premissas, a jurisprudência pátria orienta-se na direção de que não se pode impor a obrigação de reparar dano ambiental a particular que adquiriu o imóvel já com o mencionado dano, precisamente em razão de ausência de nexo causal, o que isenta a responsabilidade, ainda que objetiva, do adquirente. Confira-se:

"Dano ao meio ambiente - aquisição de terra desmatada - reflorestamento - responsabilidade - ausência - nexo causal - demonstração.

Não se pode impor a obrigação de reparar dano ambiental, através de restauração de cobertura arbórea, a particular que adquiriu a terra já desmatada. (...) Embora independa de culpa, a responsabilidade do poluidor por danos ambientais necessita de demonstração do nexo causal entre a conduta e o dano.

Recurso improvido.

(...)

Ora, o recorrente não derrubou nenhuma floresta nativa, primitiva ou regenerada e quando adquiriu a sua propriedade já não havia a reserva legal. Constitui fato incontroverso, nestes autos, a assertiva do recorrente de que adquiriu o imóvel, objeto desta ação, sem qualquer reserva de coberturaflorestal, tendo o desmatamento sido feito em épocas anteriores à sua aquisição, pelos antigos proprietários. O réu não desmatou nenhuma parte de sua fazenda.

(...)

O art. 14, $\$ 1^{\circ}$ da Lei $n^{\circ} 6.938$, de 31 de agosto de 1981, determina que o poluidor é obrigado, independentemente de culpa, a indenizar ou reparar os danos causados ao meio ambiente e a terceiros, afetados por sua atividade, mas exige nexo causal entre a conduta do recorrente e o dano, e isso não restou demonstrado e comprovado nestes autos." (grifei)

E mais:

"O art. 14, $\$ 1^{\circ}$ da Lei 6.938, de 31 de agasto de 1981, determina que o poluidor é obrigado, indepentemente da existência de culpa, a indenizar ou reparar os danos causados ao meio ambiente e a terceiros, afetados por sua atividade. No caso, não restou comprovado o nexo causal entre a conduta da recorrida e o dano ao meio ambiental.

10. Bem ambiental, São Paulo, Max Limonad, 2000, pp. 133/134

11. Recurso Espccial n² 218.120, Paraná (99/004933I-1), Rclator Ministro Garcia Vicira, DJU 1 I dc nutubro de 1999. 
(...)

Assim, não se pode qualificar como degradador do meio ambiente o proprietário do imóvel que o utiliza com sua atividade econômica em toda ou quase toda sua extensão, porque já o adquiriu com esta destinação, sendo incogitável impor-lhe a obrigação de reparar o dano através da restauração da cobertura arbórea que não destruiu."'2 (grifei)

Sendo, como visto à saciedade, imprescindivel, para a configuração da responsabilidade civil pelo dano ambiental, a existência do nexo causal, é a partir desse que se pode e deve determinar quem responde. Sobre isso, o art. $3^{\circ}$, inciso IV, considera poluidor "a pessoa física ou jurídica, de direito público ou privado, responsável, direta ou indiretamente, por atividade de degradação ambiental". Assim também o parágrafo único do art. 18 da lei dispõe que as pessoas físicas ou jurídicas “que, de qualquer modo, degradarem reservas ou estações ecológicas, bem como outras áreas declaradas como de relevante interesse ecológico, estão sujeitas às penalidades previstas no art. 14 desta lei" Vale dizer: responsável é aquele cuja atividade (ação ou omissão) guarda algum tipo de nexo de causalidade (ainda que indiretamente) com o evento danoso. A senso contrário: não pode ser responsabilizado aquele que, por sua conduta não contribuiu, de qualquer forma, para o evento danoso.

Conforme observou Adalberto Pasqualotto, "três diferentes esferas de responsabilidade podem ser distinguidas no dano ecológico. A primeira, e mais abrangente, é a que tem como figura central o responsável pela atividade ocasionadora do dano. (...) As segunda e terceira esferas dizem respeito à administração pública e aos profissionais encarregados da elaboração dos estudos de impacto ambiental"1.3 (grifei). A obrigação de reparar o dano ecológico, disse o aludido autor, "compete ao responsável pela atividade poluidora, tornando-se co-responsáveis todos os que contribuem, direta e indiretamente, para a produção do dano"14 (grifei).

É que, conforme indica a doutrina, todo o Direito Ambiental gira em torno do denominado princípio do poluidor-pagador, conceituado por Antonio Herman $\mathrm{V}$. Benjamin como "aquele que impõe ao poluidor o dever de arcar com as despesas de prevenção, reparação e repressão da poluição. Ou seja, estabelece que o causador da poluição e da degradação dos recursos nalurais deve ser o responsável principal pelas conseqüências de sua ação (ou omissão)"15 (grifei)

12. Recurso Especial n" 156.899, Paraná (97/0086051-5), Relator Ministro Garcia Vicira.

13. "Responsabilidade civil por dano ambiental: considerações de ordem material c processual", in Dano ambiental, prevenção, reparação e repressão, Coordenador Antonio Herman V. Benjamin, São Paulo, Editora RT, 1993, p. 451.

14. "Responsabilidade civil por dano ambicntal: considerações de ordem material c processual", in Dano ambiental, prevenção, reparação e repressão, Coordenador Antonio Herman V. Benjamin, São Paulo, Editora RT, 1993, p. 451.

15. "O princípio poluidor-pagador c a reparaçào do dano ambiental", in Dano ambiental, prevenção, reparação e repressão, Coordenador Antonio Herman V. Benjamin, São Paulo, Editora RT, 1993, p. 228. 
Dessa forma, o responsável pela reparação do dano ambiental, segundo observação de Rui Carvalho Piva, será qualquer pessoa abrangendo as "individualmente consideradas, as organizadas em grupo e até os entes despersonalizados. É contra estas entidades que o autor de uma ação ambiental, por exemplo, endereçará o pedido de prestação jurisdicional" 16

2. Ação Civil Pública e denunciação da lide.

De início, convém destacar que, no sistema processual civil brasileiro, há mecanismos de ampliação subjetiva do processo especificados como formas de intervenção de terceiros. Por meio de tais institutos, o terceiro (aquele que não é parte, nem coadjuvante de parte, no processo pendente ${ }^{17}$ ), torna-se parte no leito.

Dentre as diversas formas de intervenção de terceiros no processo, a figura da denunciação da lide, conforme Milton Flaks, corresponde ao "instrumento concedido a qualquer das partes do litígio para chamar a juizo um terceiro, com o qual tenha uma relą̧ão de regresso na eventualidade de perder a demanda" $1 \times$

Tem-se, então, que, para que se afigure pertinente a utilização do instrumento referido, é necessário que se apresentem seus pressupostos autorizadores: um processo pendente, uma relação de regresso entre denunciante e denunciado e dedução do requerimento no tempo e forma previstos ${ }^{19}$

Com efeito, as hipóteses específicas em que a Lei processual prevê o cabimento da denunciação da lide (art. 70, incisos I e II) acabam sintetizadas na fórmula genérica constante do inciso III do art. 70 do $\mathrm{CPC}$, que faz menção expressa à possibilidade de ressarcimento do prejuízo que vier a ser imposto à parte via ação regressiva deduzida nos próprios autos da ação originária.

Nesse sentido, anota Milton Flaks que "cabe a denúncia da lide, portanto, sempre que, em face das relações de direito material entre as partes envolvidas, ocorrer a possibilidade de decisões contraditórias, na demanda principal e na demanda regressiva, se o terceiro não ficar vinculado à primeira sentença" ${ }^{20} \mathrm{O}$ instituto, então, atende a dois princípios fundamentais: a economia processual e a harmonizą̧ão dos julgados.

16. Bem ambiental, São Paulo, Max Limonad, 2000, p. 119.

17. Cf. Athos Gusmão Carnciro, Intervençũo te terceiros, $3^{\text {a }}$ edição, São Paulo, Saraiva, 1986, p. 45 c seguintes.

18. Cf. Milton Flaks, Demunciaşão da lide, Rio de Janciro, Forense, 1984, p. 3, no qual o autor se refcre, tambćm, a Moacyr Amaral Santos.

19. Milton Flaks, obra citada, p. 162.

20. Obra citada, p. 171. Reforçando scu cntendimento, Milton Flaks traz à colação importante aresto do 1" Tribunal de Alçada Civil do Estado de Sào Paulo, que assim interpretou o instituto: "Em suma, os pressupostos objetivos da litis denuntiatio indicada no art. 70, III, do CPC, são, de um lado, a possibilidade de dano para aquele que perder a demanda, autor ou réu; é, de outro lado, uma relação juridica entre denunciante e denunciado, por força da qual este último possa vir a ser responsabilizado pelo ressarcimento, em via de regresso (Ag. I. 273.537, rel. Tito de Oliveira Heskhet)". 
A economia processual é assegurada na medida em que a inclusão de uma segunda demanda (do denunciante em face do denunciado) implica o conhecimento e instrução conjunta no processo pendente, evitando-se a instauração de novo processo.

Já a harmonização dos julgados, por meio da denunciação da lide, é assegurada porque evita julgamentos conflitantes. Sim, pois eventual processamento autônomo de cada uma das demandas poderia levar ao absurdo de, na demanda indenizatória, condenar-se o réu ao ressarcimento e, na demanda regressiva, decrelarse sua improcedência com fundamento na ausência de responsabilidade do agora autor: $E$ isso porque os efeitos da coisa julgada não se estendem aos motivos da sentença ${ }^{21}$

Impõe-se analisar, agora, a forma por meio do qual a denunciação é requerida, abordando-se, inclusive, seu cabimento no procedimento previsto pela Lei n. $7.347 / 85$.

A denunciação da lide, como cediço, há que ser requerida, pelo que se depreende do art. 71 do CPC, na petição inicial, se o autor é quem promove a intervenção, ou na contestação, se o réu é quem pretende integrar o terceiro à lide.

Além da verificação do momento oportuno para o requerimento da intervenção, cabe, ainda, aferir a viabilidade procedimental da utilização do instituto. Com efeito, há certas restrições legais ao uso da denunciação da lide, como ocorre no procedimento sumário e nas demandas que versam sobre responsabilidade civil do comerciante (arts. 13 e 88 do Código de Defesa do Consumidor). Estas restrições justificam-se pela concentração de atos e celeridade que informam tais procedimentos, sendo bastante conhecida a tese, esposada por Vicente Greco Filho ${ }^{22}$ e seguida por grande parte da doutrina e da jurisprudência, segundo a qual a "introdução de fundamento novo na lide", contrariaria as características desses procedimentos.

Este entendimento, é de se frisar, leva em consideração a distinção entre garantias próprias e garantias impróprias, distinção esta que advém do direito italiano, o qual dispõe de institutos diversos para a intervenção do terceiro conforme a garantia seja de uma espécie ou de outra. Como ensinou Calamandrei, o instituto da chiamata in garanzia reporta-se à garantia própria, decorrente da transferência de determinado bem (garantia formal ou real) ou de obrigação a pagar débito alheio (garantia pessoal ou simples). Já a garantia imprópria, entendida como mera ação regressiva, ensejaria o chamado intervento coatto ${ }^{2.3}$

Tem-se, então, que a tese restritiva da admissibilidade da denunciação da lide supõe a existência de distinção entre diferentes formas de garantia, sendo que

21. Accrca da "dupla utilidade da denunciaçào da lide", veja-sc Cândido Dinamarco, "Admissibilidade da denunciação da lide", in Revista cle processo, ano 22, n" 85, jan.-mar./97, Editora Revista dos Tribunais, São Paulo, p. 72.

22. Cf. Vicente Greco Filho, "A denunciaçào da lide, sua obrigatoricdade c extensão", in Justitia, vol. 94 c, do mesmo autor, Direito processual civil brasileiro, $10^{4}$ cdição, São Paulo, Saraiva, 1995.

23. Cf. Picro Calamandrci, Istituzioni di diritlo processuale civile secondo il niovo códice, Pádua, Ccdam, 1943, csp. p. 137. 
uma autorizaria a admissibilidade da denunciação da lide (em caso de garantia própria) e outra não.

Contudo, argumento insuperável para a admissibilidade da denunciação da lide sem a restrição acima mencionada foi trazido por Cândido Dinamarco: "o Código Buzaid, no inc. III de seu art. 70, na linha de evolução dos ordenamentos jurídicos mais avançados, passou a destinar o instituto da denunciação da lide à conservação de qualquer direito de garantia - e não mais só da garantia por evicção. Agora, então qualquer que seja a natureza da garantia e, qualquer que seja a natureza da obrigação sobre que ela incide, poderá a parte denunciar a lide ao garante"24 (grifei). Com efeito, a dicção legal (art. 70, III, do CPC) permite interpretação abrangente do instituto, vez que sua aplicação se estende àquele que estiver obrigado a indenizar em ação de regresso, qualquer que seja a espécie de garantia.

Diante desse quadro, é necessário que não se percam de vista aqueles princípios orientadores do instituto que, em vez de contrários às peculiaridades dos procedimentos que restringem a intervenção de terceiros, são compatíveis com estes. A esse propósito, o mesmo Cândido Dinamarco externou sua simpatia "pela denuncią̧ão da lide en sua configurą̧ão agora vigente no direito brasileiro, como instituto apto a otimizar a potencialidade pacificadora do processo (um processo só, só uma sentença, para a eliminação de dois conflitos)"2.5

Nesse ponto, chega-se à questão do cabimento da denunciação da lide no procedimento previsto pela Lei 7.347/85, integrado que foi pelas disposições do Título III do Código de Defesa do Consumidor. Aqui, segundo parte da doutrina, a proteção dos interesses metaindividuais não autorizaria a intervenção de terceiros, seja porque haveria a introdução de fundamento novo no processo (discussão da relação entre o denunciante e o denunciado), seja porque, nesses casos, trata-se de responsabilidade objetiva e, via de regra, a intervenção do terceiro importaria em discussão da culpa pelo evento danoso.

Diante das observações acima, pode-se refutá-lạs, mais uma vez, com o entendimento de Cândido Dinamarco, no sentido de que a introdução de elemento novo no processo, com eventual ampliação de seu objeto, deve ser admitida vez que, além da celeridade, também é objetivo do sistema processual obter "o máximo de garantia social com o mínimo de sacrifício individual da liberdade"2n Demais disso, é de se reconhecer que "todo o possivel deve ser feito para extrair do processo o máximo proveito útil" 27 . É de se dizer, ainda, que "ao Estado, que exerce a jurisdição com vista à pacificação social (e não como objetivo institucionalizado de dar satisfação

24. Cf. Cândido Rangel, Do chamamento à antoria à denuncią̧ăo da lide, Dircito Processual Civil, cap. VIII, p. 153 s., apud Cândido Dinamarco, "A admissibilidade da denunciaçào da lide", p. 69, destacou-sc.

25 Cf. Cândido Rangel Dinamarco. "Admissibilidade da denunciação da lide", in Revista de processo, ano 22, n" 85, jan.-mar./97, Sào Paulo, Editora Revista dos Tribunais, p. 69.

26. Dinamarco, “Admissibilidadc...”, p. 74.

27. Dinamarco, “Admissibilidade...”, p. 74. 
ao eventual direito do autor), interessa muito mais realizar um só processo redobradamente proveitoso, com essa reconvenção litisconsorcial que talvez, às vezes, the acrescentará alguns atos e lhe dilatará um tanto a duração, do que dois processo, duas instruções sobre o mesmo contexto de fatos, dois julgainentos que poderão conflitar entre si, em desabono da própria Justiça. Talvez o processo línico custe un pouco mais de trabalho e dedicação dos juizes, mas seria de um comodismo intolerável evitá-lo só por essa razão que nada tem a ver com o interesse público"x (grifei).

Quanto à vedação da denunciação da lide nos casos fundados em responsabilidade objetiva, é de se ter em mente que a discussão sobre o real e direto causador do dano vem a romper o nexo de causalidade, elemento sem o qual não se pode impor qualquer responsabilidade. A quebra do nexo causal exclui a responsabilidade do indigitado causador, mesmo que, para sua aferição, seja dispensado o elemento subjetivo (caracterização de dolo ou culpa do agente).

No tocante ao sistema específico da ação civil pública, integrado que é pelo Código de Defesa do Consumidor, é de se ter em mente que a disposição do art. 88 deste diploma legal, dado seu caráter limitador, há que ser interpretado restritivamente. A propósito, Cândido Dinamarco:

"O Código de Defesa do Consunidor (art. 88) veda a litisdenunciação pelo comerciante-réu a quem lhe forneceu a mercadoria, em casos de especial dificuldade para a identificação dessa pessoa. Isso não significa necessariamente que, fora das hipóteses ali indicadas, fique excluída tal modalidade de intervenção em relação às ações coletivas em geral "29 (grifei).

Segundo observou Kazuo Watanabe, "A denunciação da lide, todavia, foi vedada para o direito de regresso de que trata o art. 13, parágrafo tínico, do Código, para evitar que a tutela jurídica processual dos consumidores pudesse ser retardada e também porque, via de regra, a dedução dessa lide incidental será feita com a invocação de uma causa de pedir distinta"30 Conclui-se, portanto, que a vedação imposta pelo art. 88 do CDC limita-se às hipóteses do art. 13 da mesma lei, não se estendendo aos demais casos de ação regressiva existentes no ordenamento.

Também Rodolfo de Camargo Mancuso, tratando da intervenção do cidadão na ação civil pública, refere-se à denunciação da lide e afirma:

"Podendo, pois, ser réu, cremos não haver impedimento lógico ou legal para se admitir que ele possa ser co-réu, litisconsorte ou assistente do

28. Cândido Rangcl Dinamarco. Litisconsórcio, $4^{\star *}$ cdição, São Paulo, Malhciros, 1996, n. 81.1, csp. p. 385 .

29. Cf. Cândido Rangel Dinamarco, Intervenção de lerceiros, São Paulo, Malhciros, 1997, p. 139.

30. Cf. Watanabc, Kazuo et. al., Códligo brasileiro de defesa do constumidor, $4^{4}$ ed., Rio de Janciro, Forense Universitária, 1995, p. 534. 
réu originário e, bem assim, nomeado à autoria, chamado ao processo, denunciado à lide, conforme a natureza de sua posição jurídica en face de outras partes" 31 (grifei).

Mesmo nas hipóteses de responsabilidade objetiva, a jurisprudência do Superior Tribunal de Justiça admite a denunciação da lide, como no caso da denunciação da lide pela Fazenda Pública ao funcionário: "Cabe denunciação da lide: (...) ao servidor, pela Fazenda Pública, demandada por ato daquele (RSTJ 40/285, 58/260, maioria, 66/216; STJ-RT 667/I72; TFR-RDA 147/203, RT 6/I//28, JTA 104/30, Bol. AASP 1.022/130, RP 21/310, RBDP 43//18)".32

3 - Conclusão.

Assim sendo, conclui-se pela admissibilidade da intervenção de terceiros mediante a denunciação da lide no procedimento definido pela Lei 7.347/85, mesmo que a demanda tenha sido proposta com fundamento em responsabilidade objetiva, como ocorre em matéria ambiental.

São Paulo, março de 2002.

31. Cf. Rodolfo de Camargo Mancuso, Ação civil puiblica em defesa do meio ambiente, do patrimônio cultural e dos consumidores, $7^{\text {a }}$ ediçào, Sào Paulo, Editora Revista dos Tribunais, 2001, p. $216 / 217$.

32. Cf. Thcotonio Negrão, Código de processo civil e legislação processual em vigor, 32: cdiçào, São Paulo, Editora Saraiva, p. 172. 